\title{
Efficacy of Oral Gabapentin for Attenuation of Haemodynamic Responses to Laryngoscopy \& Endotracheal Intubation
}

\author{
Bhavitha Venigalla ${ }^{1}$, Sanjot Sudhir Ninave ${ }^{2}$ \\ 1, 2 Department of Anaesthesiology, Datta Meghe Institute of Medical Sciences, \\ Sawangi, Wardha, Maharashtra, India.
}

\section{ABSTRACT}

\section{BACKGROUND}

Laryngoscopy and endotracheal intubation are basic skills to be acquired by an anaesthesiologist. For many years, laryngoscopy has been used as a conventional way to facilitate endotracheal intubation. These are the most critical events because, they provoke a marked rise in sympathoadrenal response as hypertension and tachycardia. There is an absolute need to decrease these haemodynamic responses, for which various drugs were used, with varying degrees of success. Gabapentin, initially used as an anticonvulsant has extended its role into anaesthesia practice with its multimodal effects. This study was conducted to evaluate the efficacy of oral gabapentin $800 \mathrm{mg}$ in attenuation of haemodynamic responses to laryngoscopy and endotracheal intubation.

\section{METHODS}

After obtaining institutional ethical clearance, a prospective randomised comparative study was undertaken. Written and informed consent was obtained from 80 patients belonging to American Society of Anaesthesiologists (ASA) class I \& II scheduled for various elective surgeries under general anaesthesia. They were divided into two groups of 40 each using computer generated random number table. Group G received oral gabapentin $800 \mathrm{mg}$ and group C received empty capsules with sips of water, 2 hours prior to induction. Haemodynamic parameters - heart rate (HR), systolic blood pressure (SBP), diastolic blood pressure (DBP), mean arterial pressure (MAP) were noted and rate pressure product (RPP) was calculated at baseline, at laryngoscopy and then at 1, 3, 5, $10 \& 15$ minutes after laryngoscopy and endotracheal intubation.

\section{RESULTS}

In Group G there was significant attenuation of HR, SBP, DBP, MAP at 1, 3 and 5 minutes after laryngoscopy and endotracheal intubation as compared to Group C. Hence, in Group G there was significant attenuation of RPP at 1 minute (12673.60 \pm $1691.25,11769.08 \pm 1146.02, \mathrm{P}=0.01), 3$ minutes $(12546.85 \pm 1123.78,11759.98 \pm$ $1358.02, \mathrm{P}=0.01)$ and 5 minutes $(12411.68 \pm 1270.04,11537.03 \pm 1230.06, \mathrm{P}=$ 0.002 ) after laryngoscopy and endotracheal intubation as compared to Group C. No statistical difference was seen at 10 and 15 minutes.

\section{CONCLUSIONS}

Oral gabapentin $800 \mathrm{mg}$ given preoperatively can attenuate haemodynamic responses to laryngoscopy and endotracheal intubation without significant side effects.

\section{KEY WORDS}

Oral Gabapentin, Laryngoscopy, Endotracheal Intubation, Haemodynamic Changes, Attenuation, Pressor Responses
Corresponding Author: Dr. Sanjot Sudhir Ninave, Department of Anaesthesiology, AVBRH Sawangi, Wardha, Maharashtra, India.

E-mail: bhavitha123@gmail.com

DOI: $10.14260 /$ jemds/2021/194

How to Cite This Article:

Venigalla B, Ninave SS. Efficacy of oral gabapentin for attenuation of haemodynamic responses to laryngoscopy \& endotracheal intubation. J Evolution Med Dent Sci 2021;10(12):905-909, DOI: 10.14260/jemds/2021/194

Submission 13-11-2020,

Peer Review 27-01-2021,

Acceptance 04-02-2021,

Published 22-03-2021.

Copyright (C) 2021 Bhavitha Venigalla et al This is an open access article distributed under Creative Commons Attribution License [Attribution 4.0 International (CC $B Y 4.0)]$ 


\section{BACKGROUND}

Airway management \& endotracheal intubation are a fundamental and essential skill to be acquired for a safeconduct of anaesthesia. From the mid of $20^{\text {th }}$ century laryngoscopy \& endotracheal intubation has become an essential part of the induction of general anaesthesia. "Tracheal intubation" is termed as the positioning of a flexible plastic tube into the trachea to maintain a patent airway and to serve as a medium to administer oxygen and inhalational agents. ${ }^{1,2}$

As early as in 1940's, Reid and Brace et al. were the first to recognize haemodynamic responses to laryngoscopy and tracheal intubation. ${ }^{3}$ An increase in sympathoadrenal activity results in hypertension, tachycardia and arrhythmias. ${ }^{4,5}$ This transitory increase in haemodynamic variables like blood pressure and heart rate are variable \& unpredictable. ${ }^{6}$ Usually, this sympathoadrenal response occurs $30 \mathrm{sec}$ after laryngoscopy and intubation and lasts for less than 10 minutes. ${ }^{7}$ Although the normal haemodynamic response to intubation is seen in all patients but healthy individuals tolerate it better. In few patients, these responses prove to be detrimental to the health or the successful outcome of the procedure. There is increased mortality and morbidity in patients suffering from cardiovascular or cerebral disease due to tachycardia and hypertension ${ }^{8}$ and also can lead to potentially serious complications of the cardiovascular and central nervous system like myocardial ischemia, ${ }^{9}$ left ventricular failure, pulmonary oedema, 10 ventricular dysrhythmias $^{5}$ and cerebral haemorrhage. ${ }^{11}$ These are the reasons why there is an absolute need for attenuation of pressor response to laryngoscopy and endotracheal intubation.

Wycoff C.C et al. in 1960 in his study stated that intubation done under superior laryngeal nerve blocks along with topical anaesthesia spray of the pharynx reduced the increase in mean arterial pressure after intubation. ${ }^{12}$ Since then various modalities have been proposed and practiced to control the haemodynamic and the catecholamine responses to laryngoscopy and endotracheal intubation, but no single technique is proven to be effective in avoiding or attenuating such pressor responses. Many drugs like clonidine, ${ }^{13}$ fentanyl, ${ }^{14}$ dexmedetomidine, ${ }^{15,16}$ paracetamol,17 esmolol ${ }^{15,18}$ and lignocaine ${ }^{19}$ and others used to attenuate the pressor response were either partially effective or their use showed undesirable side effects.

Gabapentin was initially used as an anticonvulsant. A structural analogue of gamma-aminobutyric acid has extended its role into anaesthesia practice with its multimodal effects such as for providing preoperative anxiolysis, post-operative analgesia, preventing postoperative nausea and vomiting and delirium. ${ }^{20}$ It is seen in some studies that gabapentin can attenuate pressor response occurring during laryngoscopy and tracheal intubation, and this propitious effect is probably due to inhibition of calcium gate voltage channels, similar to that of calcium channel blockers. ${ }^{21,22}$ So, we have decided to study the efficacy of oral gabapentin $800 \mathrm{mg}$ in attenuation of haemodynamic responses to laryngoscopy and tracheal intubation.

\section{METHODS}

After institutional ethical committee clearance was obtained, this prospective randomised comparative study was carried out in the Department of Anaesthesiology, DMIMS Sawangi (Meghe), Wardha from August 2018 to August 2020. Openepi.com was used for sample size calculation. Assuming mean heart rate of 83.6 beats per minute with a standard deviation of 12.1 beats per minute (with reference study done by Memis D et al. ${ }^{21}$ keeping power at $80 \%$ and confidence intervals at $95 \%$ (alpha error at 0.05 ), a sample of 37 patients was be required to detect a minimum of $10 \%$ difference in the heart rate between the two groups. We included 40 patients in each group to compensate for possible dropouts i.e. total 80 patients. This study was carried out on 80 patients (after obtaining sample size) of age group between 20 to 60 years of ASA I and II posted for various non-cardiac elective surgery requiring general anaesthesia with endotracheal intubation fulfilling the inclusion and exclusion criteria. Patients with ASA class III and above, anticipated difficult intubation, any known allergy to study drug, patients on beta-blockers or calcium channel blockers or sympatholytic drugs were excluded from out study. Double blinding was done. Pre-anaesthetic evaluation was done and written and informed consent was taken. All patients were asked to be nil by mouth for 6 hours. Patients were divided into 2 groups of 40 each, by computer generated random number table. Group G and Group C received oral gabapentin $800 \mathrm{mg}$ and empty capsules respectively, 2 hours prior to induction of anaesthesia. Patients were monitored for side effects of drugs like somnolence, drowsiness, nausea and vomiting. Patients having somnolence, drowsiness were reassured and observed and given $100 \%$ oxygen through Hudson mask, under SpO2 and heart rate monitoring. Patients having nausea and vomiting were given injection ondansetron $4 \mathrm{mg}$.

On arrival in the operation theatre, multipara monitors were attached, baseline haemodynamic parameters were noted. Intravenous (IV) line was secured with 18 G Cannula and IV fluid Ringer's lactate was started. Routine conventional pre medications were given intravenously i.e. injection glycopyrrolate $0.004 \mathrm{mg} / \mathrm{kg}$, injection midazolam $0.05 \mathrm{mg} /$ $\mathrm{kg}$ and injection fentanyl $2 \mathrm{mcg} / \mathrm{kg}$. Patients were preoxygenated with $100 \%$ oxygen. Induction by injection propofol $2 \mathrm{mg} / \mathrm{kg}$ intravenously till loss of eyelash reflex and injection vecuronium bromide $0.1 \mathrm{~g} / \mathrm{kg}$ IV was given after confirming the mask ventilation. After an interval of 3 minutes, when the neuromuscular block was achieved laryngoscopy and intubation was performed by an experienced anaesthesiologist. Heart rate, SBP, DBP, and MAP were noted at laryngoscopy-intubation and at 1, 3, 5, 10 and 15 minutes. Patients were ventilated with closed circuit and anaesthesia was maintained on $\mathrm{O}_{2}(50 \%), \mathrm{N}_{2} 0$ (50\%), sevoflurane (MAC 1.5 - $2.0 \%$ ), and injection vecuronium bromide. For monitoring purpose HR, SBP, DBP, and MAP were noted at 1 , 3, 5, 10 \& 15 minutes after laryngoscopy and intubation. They were labelled as T1, T3, T5, T10 \& T15 respectively. RPP was calculated at all-time intervals by multiplying the SBP and HR. Further anaesthesia protocol was continued according to the conventional manner, according to that particular surgery. At the end of the procedure, patients were reversed using injection neostigmine $0.05 \mathrm{mg} / \mathrm{kg}$ and injection glycopyrrolate $0.004 \mathrm{mg} / \mathrm{kg}$ intravenously and extubated 
after fulfilling extubation criteria. Later patients were shifted to recovery room for monitored post-operative care.

\section{Statistical Analysis}

Qualitative data was presented with the help of the percentage table, the association among the study groups was assessed with the help of the chi-square test. Quantitative data was presented as mean and standard deviation, comparison among the study groups was done with the help of Student's t-test. Software used in the analysis was Statistical Package for the Social Sciences (SPSS) 20.0 version and $\mathrm{P}<0.05$ was considered statistically significant.

\section{RESULTS}

\begin{tabular}{|cccc|}
\hline Variables & $\begin{array}{c}\text { Group C }(\mathbf{N}=\mathbf{4 0}) \\
\text { Mean } \pm \text { SD }\end{array}$ & $\begin{array}{c}\text { Group G (N = 40) } \\
\text { Mean } \pm \text { SD }\end{array}$ & P-Value \\
\hline Age (Years) & $36.2 \pm 10.8$ & $36.72 \pm 10.6$ & $\mathrm{P}=0.82(\mathrm{NS})$ \\
Gender (M / F) & $19 / 21(47.5 \% / 52.5 \%)$ & $18 / 22(45 \% / 55 \%)$ & $\mathrm{P}=0.8226(\mathrm{NS})$ \\
ASA I / II & $24 / 16(60 \% / 40 \%)$ & $24 / 16(60 \% / 40 \%)$ & $\mathrm{P}=1(\mathrm{NS})$ \\
Weight & $65.38 \pm 14.43$ & $67.90 \pm 14.56$ & $\mathrm{P}=0.44(\mathrm{NS})$ \\
\hline \multicolumn{4}{|c|}{ Table 1. Demographic Details } \\
\hline *( NS-Non significant; S-Significant ; P $<0.05$ is considered as significant ) \\
\hline
\end{tabular}

Table 1 depict the demographic details of the patients were not statistically significant when compared between both the groups.

\begin{tabular}{|cccc|}
\hline Time Interval & Group C Mean \pm SD & Group G Mean \pm SD & P-Value \\
Baseline & $89.78 \pm 11.8$ & $89.73 \pm 10.82$ & $0.9843(\mathrm{NS})$ \\
At laryngoscopy & $95.95 \pm 10.13$ & $94.15 \pm 11.06$ & $0.4500(\mathrm{NS})$ \\
T1 & $95.88 \pm 9.5$ & $92.19 \pm 6.78$ & $0.0497(\mathrm{~S})$ \\
T3 & $95.55 \pm 6.95$ & $92.08 \pm 8.27$ & $0.0454(\mathrm{~S})$ \\
T5 & $95.20 \pm 6.6$ & $91.18 \pm 8.24$ & $0.0185(\mathrm{~S})$ \\
T10 & $91.45 \pm 11.27$ & $90.28 \pm 12.67$ & $0.6624(\mathrm{NS})$ \\
T15 & $91.68 \pm 12.03$ & $90.13 \pm 9.97$ & $0.5323(\mathrm{NS})$ \\
\hline \multicolumn{4}{|r}{ Table 2. Comparison of HR between the Two Groups } \\
\hline
\end{tabular}

\begin{tabular}{|c|c|c|c|c|c|c|}
\hline \multirow[b]{2}{*}{$\begin{array}{c}\text { Time } \\
\text { Interval }\end{array}$} & \multicolumn{3}{|c|}{ SBP } & \multicolumn{3}{|c|}{ DBP } \\
\hline & $\begin{array}{c}\text { Group C } \\
\text { Mean } \pm \\
\text { SD }\end{array}$ & $\begin{array}{c}\text { Group G } \\
\text { Mean } \pm \\
\text { SD }\end{array}$ & $P$ value & $\begin{array}{c}\text { Group C } \\
\text { Mean } \pm \\
\text { SD }\end{array}$ & $\begin{array}{c}\text { Group G } \\
\text { Mean } \pm \\
\text { SD }\end{array}$ & P-Value \\
\hline Baseline & $\begin{array}{r}124.35 \\
\pm 8.26\end{array}$ & $\begin{array}{r}124.90 \\
\pm 10.71\end{array}$ & $\begin{array}{l}0.7978 \\
(\mathrm{NS})\end{array}$ & $\begin{array}{l}76.85 \\
\pm 8.42\end{array}$ & $\begin{array}{l}76.15 \\
\pm 8.36\end{array}$ & $\begin{array}{l}0.710 \\
\text { (NS) }\end{array}$ \\
\hline $\begin{array}{c}\text { At } \\
\text { laryngoscopy }\end{array}$ & $\begin{array}{r}133.63 \\
\pm 6.15\end{array}$ & $\begin{array}{r}132.85 \\
\pm 7.15\end{array}$ & $\begin{array}{l}0.6046 \\
(\mathrm{NS})\end{array}$ & $\begin{array}{l}81.33 \\
\pm 8.16\end{array}$ & $\begin{array}{l}80.90 \\
\pm 7.56\end{array}$ & $\begin{array}{l}0.809 \\
\text { (NS) }\end{array}$ \\
\hline $\mathrm{T} 1$ & $\begin{array}{l}131.95 \\
\pm 9.12\end{array}$ & $\begin{array}{l}127.75 \\
\pm 9.28\end{array}$ & $\begin{array}{l}0.0446 \\
(S)\end{array}$ & $\begin{array}{l}81.70 \\
\pm 9.76\end{array}$ & $\begin{array}{l}77.85 \\
\pm 6.77\end{array}$ & $\begin{array}{c}0.044 \\
(S)\end{array}$ \\
\hline T3 & $\begin{array}{l}131.33 \\
\pm 7.22\end{array}$ & $\begin{array}{l}127.60 \\
\pm 7.39\end{array}$ & $\begin{array}{l}0.0253 \\
(\mathrm{~S})\end{array}$ & $\begin{array}{l}80.83 \\
\pm 6.14\end{array}$ & $\begin{array}{l}77.95 \\
\pm 5.61\end{array}$ & $\begin{array}{c}0.031 \\
(\mathrm{~S})\end{array}$ \\
\hline $\mathrm{T} 4$ & $\begin{array}{r}130.25 \\
\pm 8.18\end{array}$ & $\begin{array}{l}126.55 \\
\pm 7.75\end{array}$ & $\begin{array}{l}0.0412 \\
(S)\end{array}$ & $\begin{array}{l}80.53 \\
\pm 6.99\end{array}$ & $\begin{array}{l}77.55 \\
\pm 6.28\end{array}$ & $\begin{array}{c}0.048 \\
(\mathrm{~S})\end{array}$ \\
\hline T5 & $\begin{array}{l}126.78 \\
\pm 9.12\end{array}$ & $\begin{array}{r}126.55 \\
\pm 6.93\end{array}$ & $\begin{array}{l}0.9015 \\
(\mathrm{NS})\end{array}$ & $\begin{array}{l}77.18 \\
\pm 9.57\end{array}$ & $\begin{array}{l}76.78 \\
\pm 6.42\end{array}$ & $\begin{array}{c}0.826 \\
(\mathrm{NS})\end{array}$ \\
\hline T6 & $\begin{array}{l}126.90 \\
\pm 9.25\end{array}$ & $\begin{array}{l}126.70 \\
\pm 9.54\end{array}$ & $\begin{array}{c}0.9244 \\
\text { (NS) }\end{array}$ & $\begin{array}{c}77.23 \pm \\
10.47\end{array}$ & $\begin{array}{l}76.80 \\
\pm 8.14\end{array}$ & (NS) \\
\hline
\end{tabular}

\begin{tabular}{|c|c|c|c|}
\hline Time Interval & Group C Mean : & up G Mean \pm SD & P-Value \\
\hline Baseline & $92.68 \pm 6.75$ & $92.40 \pm 7.79$ & 0.8624 (NS) \\
\hline At laryngoscopy & $98.76 \pm 6.64$ & $98.22 \pm 5.59$ & 0.6942 (NS) \\
\hline $\mathrm{T} 1$ & $98.45 \pm 7.19$ & $94.48 \pm 6.96$ & $0.0142(\mathrm{~S})$ \\
\hline T3 & $97.66 \pm 4.68$ & $94.50 \pm 5.01$ & $0.0047(\mathrm{~S})$ \\
\hline T5 & $97.10 \pm 4.33$ & $93.88 \pm 5.33$ & $0.0041(S)$ \\
\hline T10 & $93.71 \pm 7.28$ & $93.37 \pm 5.81$ & $0.8172(\mathrm{NS})$ \\
\hline T15 & $93.78 \pm 8.15$ & $93.43 \pm 7.30$ & $0.8402(\mathrm{NS})$ \\
\hline \multicolumn{4}{|c|}{ Table 4. Comparison of MAP between the Two Groups } \\
\hline
\end{tabular}

\begin{tabular}{|cccc|}
\hline Time Interval & $\begin{array}{c}\text { Group C } \\
\text { Mean } \pm \text { SD }\end{array}$ & $\begin{array}{c}\text { Group G } \\
\text { Mean } \pm \text { SD }\end{array}$ & P-Value \\
\hline Baseline & $11159.45 \pm 1608.18$ & $11178.40 \pm 1490.34$ & $0.96(\mathrm{NS})$ \\
At laryngoscopy & $12813.23 \pm 1398.34$ & $12495.65 \pm 1533.14$ & $0.34(\mathrm{NS})$ \\
T1 & $12673.60 \pm 1691.25$ & $11769.08 \pm 1146.02$ & $0.01(\mathrm{~S})$ \\
T3 & $12546.85 \pm 1123.78$ & $11759.98 \pm 1358.02$ & $0.01(\mathrm{~S})$ \\
T5 & $12411.68 \pm 1270.04$ & $11537.03 \pm 1230.06$ & $0.002(\mathrm{~S})$ \\
T10 & $11597.50 \pm 1657.93$ & $11404.25 \pm 1598.97$ & $0.60(\mathrm{NS})$ \\
T15 & $11654.05 \pm 1878.78$ & $11425.80 \pm 1553.67$ & $0.56(\mathrm{NS})$ \\
\hline \multicolumn{4}{|c}{ Table 5. Comparison of RPP between the Two Groups } \\
\hline \multicolumn{4}{|r}{}
\end{tabular}

Tables 2 to 5 depicts the haemodynamic parameters - HR, SBP, DBP, MAP and RPP calculated from SBP $x$ HR were significantly attenuated at 1,3 and 5 minutes i.e. T1, T3 and T5 respectively $(\mathrm{P}<0.05)$.

\section{DISCUSSION}

During the administration of general anaesthesia in patients, the most crucial events are the laryngoscopy and endotracheal intubation, because they can provoke transient, yet significant sympathoadrenal response presenting as hypertension and tachycardia. ${ }^{5}$ Similarly, any haemodynamic reflex stimulation which can also occur during extubation, these responses also need to be attenuated using various drugs like esmolol, dexmedetomidine and others. ${ }^{15}$ Reid et al. in 1940 found that due to stimulation of the upper respiratory tract, it provoked an increase in vagal activity. ${ }^{3}$ But Burstein et al. in 1950 contradicted Reid's testimony and stated that the pressor response is a result of stimulation of epipharynx and laryngopharynx resulting in increased sympathetic response. ${ }^{23}$ Prys-Robert in 1971 further confirmed these factors. ${ }^{5}$ King et al. in 1951 for abolishing reflex circulatory responses to tracheal intubation, employed deep ether anaesthesia. ${ }^{24}$

Gabapentin is a structural analogue of GABA (gamma amino butyric acid), a neurotransmitter. It acts on GABA-B receptors, leading to its activation and it also enhances $\mathrm{N}$ methyl-D-aspartate (NMDA) current at GABAergic interneurons. Gabapentin was primarily used for epilepsy, later it was used for the management of chronic pain, anxiolysis, analgesia in the postoperative period and also to aid in attenuation of pressor response to laryngoscopy and tracheal intubation. Oral gabapentin is well absorbed from the gastrointestinal tract. Peak plasma concentrations are reached at 2 - 3 hours after oral ingestion and elimination half-life is 5 - 7 hours. ${ }^{25}$ Although the mechanism behind how gabapentin attenuates the pressor response to laryngoscopy and tracheal intubation is not well understood. The possible mechanism may be inhibiting the voltage-gated calcium $\left(\mathrm{Ca}^{+}\right)$channels in the vessels by vasodilating them, and by acting directly on pharynx muscles causing relaxation and further by its effects on descending noradrenergic and spinal alpha-2 adrenergic system. ${ }^{26,27}$ In our study, we found that both the groups were well matched with respect to age, gender, weight and ASA status. Haemodynamic parameters such as heart rate, systolic blood pressure, diastolic blood pressure and mean arterial pressure has significantly decreased in Group $G$ when compared to group $\mathrm{C}$ at $1,3 \& 5$ minute after laryngoscopy and tracheal intubation. Rate pressure product (RPP) is a quantity which is the product of the SBP and HR at any given moment. It correlates well with the myocardial oxygen consumption and bears a constant relationship to the onset of angina 
pectoris in any patient with ischemic heart disease. The RPP was better attenuated in Group G compared to group C at 1, 3 $\& 5$ minutes after laryngoscopy and tracheal intubation. With respect to side effects, one patient had somnolence and two patients had drowsiness. No major side effects were noted. Similar results were seen in a study conducted by Memis D et al. in $2006^{21}$ as they reported heart rate and mean arterial pressure was significantly low in patients receiving gabapentin $800 \mathrm{mg}$ up to 10 minutes after induction as compared to the group receiving $400 \mathrm{mg}$. Other studies by Kiran et al. in $2008^{28}$ and Bhandari et al. in $2012^{29}$ showed similar results. Iftikhar et al. in $2011^{30}$ showed significant attenuation of SBP, DBP, MAP and HR. In our study Attenuation in heart rate was noticed by use of oral gabapentin $800 \mathrm{mg}$. In a study conducted by Kumari I et al. in 200931 showed significant attenuation of systolic blood pressure and diastolic blood pressure in the group receiving gabapentin $900 \mathrm{mg}$. Another study by Kiran et al. in $2008^{28}$ showed that diastolic blood pressure and mean arterial pressure was significantly attenuated at 1 and 3 minutes after intubation in patients who received gabapentin. Whereas Fassoulaki et al. in $2006^{22}$ conducted a study using higher doses i.e. $1600 \mathrm{mg}$ of gabapentin (1600 mg divided into 4 equal doses over 24 hours) in comparison with placebo capsules which showed significant attenuation of diastolic blood pressure when compared to the control group at up to 10 minutes after laryngoscopy and tracheal intubation. They have not studied about side effects. But in our study, we have observed similar results using oral gabapentin $800 \mathrm{mg}$, single dose given 2 hours prior to induction. Rate pressure product was better attenuated in the group receiving oral gabapentin although similar results were obtained by Chandapet S et al. in 2017,32 showed that RPP values were significantly lower in the gabapentin group at laryngoscopy and at 1, 3, 5, and $10 \mathrm{~min}$ after intubation when compared to the control group. In contrary to our study, there are other studies where gabapentin was compared with clonidine. In a study by Madhuri et al. in $2019^{33}$ clonidine $0.3 \mathrm{mg}$ was better in reducing RPP compared to gabapentin but it was found to be statistically insignificant. The other study by Joshi et al. in $2017^{34}$ compared gabapentin $900 \mathrm{mg}$ to oral clonidine $300 \mu \mathrm{g}$ for reducing pressor response and observed that clonidine had significantly attenuated the pressor response compared to gabapentin.

\section{CONCLUSIONS}

Oral gabapentin $800 \mathrm{mg}$ when given 2 hours before surgery as a premedication helps in attenuation of haemodynamic responses to laryngoscopy and endotracheal intubation without any serious side effects.

Data sharing statement provided by the authors is available with the full text of this article at jemds.com.

Financial or other competing interests: None.

Disclosure forms provided by the authors are available with the full text of this article at jemds.com.

\section{REFERENCES}

[1] Ezri T, Evron S, Hadad H, et al. Tracheostomy and endotracheal intubation: a short history. Harefuah 2005;144(12):891-908.

[2] Moore MW, Rauscher LA. A complication of oropharyngeal airway placement. Anesthesiology 1977;47(6):526.

[3] Reid LC, Brace DE. Irritation of the respiratory tract and its reflex effect upon heart. Surg Gynecol Obs 1940;70:157-62.

[4] Stoelting RK. Blood pressure and heart rate changes during short-duration laryngoscopy for tracheal intubation: influence of viscous or intravenous lidocaine. Anesth Analg 1978;57(2):197-9.

[5] Prys-Roberts C, Greene LT, Meloche R, et al. Studies of anaesthesia in relation to hypertension. II. Haemodynamic consequences of induction and endotracheal intubation. Br J Anaesth 1971;43(6):53147.

[6] Fujii Y, Saitoh Y, Takahashi S, et al. Diltiazem-lidocaine combination for the attenuation of cardiovascular responses to tracheal intubation in hypertensive patients. Can J Anesth 1998;45(10):933-7.

[7] Stoelting RK. Circulatory changes during direct laryngoscopy and tracheal intubation: influence of duration of laryngoscopy with or without prior lidocaine. Anesthesiology 1977;47(4):381-4.

[8] Aronson S, Fontes ML. Hypertension: a new look at an old problem. Curr Opin Anesthesiol 2006;19(1):59-64.

[9] Dalton B, Guiney T. Myocardial ischemia from tachycardia and hypertension in coronary heart diseasepatients undergoing anaesthesia. Bost Ann Mtg Am Soc Anaesthesiol 1972;20:1-2.

[10] Fox EJ, Sklar GS, Hill CH, et al. Complications related to the pressor response to endotracheal intubation. Anesthesiology 1977;47(6):524-5.

[11] Donegan MF, Bedford RF. Intravenously administered lidocaine prevents intracranial hypertension during endotracheal suctioning. Anesthesiology 1980;52(6):516-7.

[12] Wycoff CC. Endotracheal intubation: effects on blood pressure and pulse rate. Anesthesiology 1960;21:153-8.

[13] Charan N, Hijam B, Ninave S, et al. A double blind comparative study of IV. Clonidine and fentanyl to see the haemodynamic response during laryngoscopy and intubation. J Evol Med Dent Sci 2014;3(39):10015-25.

[14] Samuel H, Melekamayhu A, Woldeyohannes M, et al. A comparative study between intravenous fentanyl and intravenous lidocaine on attenuation of hemodynamic pressor responses to laryngoscopic intubation: a prospective cohort study, Ethiopia. Open Journal of Anesthesiology 2019;9(9):167-78.

[15] Tendulkar MP, Ninave SS. Prospective comparison of pressor and airway responses to IV esmolol and IV dexmedetomidine during emergence from general anaesthesia and extubation. Journal of Krishna Institute of Medical Sciences University 2017;6(1):49-56.

[16] Scheinin B, Lindgren L, Randell $\mathrm{T}$, et al. Dexmedetomidine attenuates sympathoadrenal responses to tracheal intubation and reduces the need for thiopentone and peroperative fentanyl. Br J Anaesth 1992;68(2):126-31. 
[17] Dalal S, Ninave S. Efficacy of intravenous paracetamol infusion for attenuation of hemodynamic responses to laryngoscopy and tracheal intubation. Indian Journal of Sciences and Technology 2019;12(36):1-7.

[18] Singh H, Vichitvejpaisal P, Gaines GY, et al. Comparative effects of lidocaine, esmolol and nitroglycerin in modifying the hemodynamic response to laryngoscopy and intubation. J Clin Anesth 1995;7(1):5-8.

[19] Hosalli V, Es A, Hulkund SY, et al. Comparative efficacy of different doses of fentanyl on cardiovascular responses to laryngoscopy and tracheal intubation. J Clin Diagn Res 2014;8(9):5-7.

[20] Kong VKF, Irwin MG. Gabapentin: a multimodal perioperative drug? Br J Anaesth 2007;99(6):775-86.

[21] Memis D, Turan A, Karamanlioğlu B, et al. Gabapentin reduces cardiovascular responses to laryngoscopy and tracheal intubation. Eur J Anaesthesiol 2006;23(8):68690.

[22] Fassoulaki A, Melemeni A, Paraskeva A, et al. Gabapentin attenuates the pressor response to direct laryngoscopy and tracheal intubation. Br J Anaesth 2006;96(6):76973.

[23] Burstein CL, Lopinto FJ, Newman W. Electrocardiographic studies during endotracheal intubation. I. Effects during usual routine technics. Anesthesiology 1950;11(2):224-37.

[24] King BD, Harris LC, Greifenstein FE, et al. Reflex circulatory responses to direct laryngoscopy and tracheal intubation performed during general anesthesia. Anesthesiology 1951;12(5):556-66.

[25] Urs NS, Shobha D. Comparative evaluation of oral gabapentin and pregabalin premedication for attenuation of pressor response to endotracheal intubation under general anaesthesia. International Journal of Science and Research 2014;3(11):654-8.

[26] Alden KJ, García J. Differential effect of gabapentin on neuronal and muscle calcium currents. J Pharmacol Exp
Ther 2001;297(2):727-35.

[27] Tanabe M, Takasu K, Kasuya N, et al. Role of descending noradrenergic system and spinal alpha2-adrenergic receptors in the effects of gabapentin on thermal and mechanical nociception after partial nerve injury in the mouse. Br J Pharmacol 2005;144(5):703-14.

[28] Kiran S, Verma D. Evaluation of gabapentin in attenuating pressor response to direct laryngoscopy and tracheal intubation. South African Journal of Anaesthesia and Analgesia 2008;14(6):43-6.

[29] Bhandari G, Shahi KS. Effect of gabapentin on pressor response to laryngoscopy and tracheal intubation: a double blind randomized placebo controlled study. People's Journal of Scientific Research 2013;6(1):1-6.

[30] Iftikhar T, Taqi A, Sibtain A, et al. Oral gabapentin reduces hemodynamic response to direct laryngoscopy and tracheal intubation. Anaesth, Pain and Intensive Care 2011;15(1):17-20.

[31] Kumari I, Pathania VS. A prospective randomised double-blind placebo controlled trial of oral gabapentin in attenuation of haemodynamic responses during laryngoscopy and tracheal intubation. Journal of Anaesthesiology Clinical Pharmacology 2009;25(4):439-43.

[32] Chandapet S, Fatima F. To study effect of Gabapentin on attenuation of pressor response to direct laryngoscopy and tracheal intubation and on perioperative pain. J Evid Based Med Healthc 2017;4(43):2659-62.

[33] Madhuri P, Grandhi MP. A Comparative study of oral clonidine versus oral gabpentin premedication in attenuation of pressor response during laryngoscopy and enotracheal intubation. International Journal of Scientific Research 2019;8(6):10-2.

[34] Joshi S, Kumar A, Shah H. Clonidine versus oral gabapentin as premedication for obtunding hemodynamic response to laryngoscopy and tracheal intubation. Ind J Appl Res 2017;7(9):32-6. 